\title{
Research Article \\ CD3/CD19 Depletion for T-cell Reduction of Allogeneic Transplants: Mostly Efficient, but not Robust
}

\author{
Eliza Wiercinska ${ }^{1}$, Erhard Seifried ${ }^{1,2,(1)}$, Halvard Bonig $^{1,2,3, *},(\mathbb{D})$ \\ ${ }^{1}$ German Red Cross Blood Service Baden-Württemberg-Hessen, Institute Frankfurt, Frankfurt a.M., Germany \\ ${ }^{2}$ Institute for Transfusion Medicine and Immunohematology, Goethe University, Frankfurt a.M., Germany \\ ${ }^{3}$ Department of Medicine/Division of Hematology, University of Washington, Seattle, WA, USA
}

\section{ARTICLE INFO}

\section{Article History}

Received 05 May 2021

Accepted 21 July 2021

\section{Keywords}

Immunomagnetic depletion CliniMACS

haplo-identical transplantation TCR $\alpha \beta /$ CD19 depletion graft-versus-host disease graft failure

\begin{abstract}
Aggressive T-cell depletion, in vitro or in vivo, is a prerequisite for survival of haplo-identical stem cell transplantation. The classical T-cell-depleted transplant, immunomagnetically enriched CD34+ cells, is very safe with respect to graft-versus-host reactivity, but associated with very high transplant-related and relapse mortality with an overall probability of survival of only $20 \%$. Protocols for T- and B-cell depletion were therefore developed, reasoning that transplantation of the majority of Natural Killer (NK) cells and the substantial dose of residual T-cells might improve survival, which was, in principle, confirmed. Anecdotal reports of frequent failure to achieve adequate T-cell depletion prompted review of the aggregate data for transplant quality at our center. The first observation is the relative paucity of combined CD3/CD19 depletion processes as PTCy protocols have made inroads, 13 depletions in 8 years. Median T- and B-cell log-depletion were -3.89 and -1.92 , respectively; instead of, CD34+ cell recovery was generally high (median 92\%), as was NK-cell recovery (median 52\%). However, the process failed to yield satisfactory T- and B-cell depletion in two out of 13 preparations, of which one product could be rescued by a second round of depletion, at the expense of CD34+ cell recovery. In our hands, the process is thus insufficiently robust for routine clinical use. Assuming similar observations in other centers, this may explain implementation of alternative protocols, such as TCR $\alpha \beta / \mathrm{CD} 19$ depletion or transplantation of unmanipulated grafts with subsequent in vivo depletion.
\end{abstract}

(c) 2021 International Academy for Clinical Hematology. Publishing services by Atlantis Press International B.V. This is an open access article distributed under the CC BY-NC 4.0 license (http://creativecommons.org/licenses/by-nc/4.0/).

\section{INTRODUCTION}

Where well-matched donors are unavailable, transplant centers may resort to mismatched donors, most often haplo-identical family donors [1-3]. Such transplants will inevitably cause lethal acute graft-versus-host disease (GvHD) unless T-cells are aggressively depleted. The price for overzealous T-cell depletion, on the other hand, is graft failure, relapse due to lack of immunological control of residual blasts (graft-versus-leukemia, GvL), morbidity and mortality from opportunistic infections and dramatically delayed immune reconstitution [4-7]. The search for the ideal protocols providing GvHD control and useful immune function has been ongoing for approximately four decades, but achieving good separation of GvHD from GvL immune response is notoriously difficult. The initial haplo-identical transplant required mega-doses of CD34+ cells [8,9], immunomagnetically selected by, at the time, several competing technologies [10-12]. The disappointing clinical outcomes, with long-term survival rates of not much more than $20 \%$ [7], have largely curbed the enthusiasm for allogeneic "naked haplo" transplantation without immediate or delayed co-transplantation of an alloreactivity-attenuated T-cell product [7]. The use of CD34+ selected products is limited to

"Corresponding author. Email: h.boenig@blutspende.de; hbonig@uw.edu Peer review under responsibility of the International Academy for Clinical Hematology Data availability statement: Anonymized raw data will be made available to interested readers upon reasonable request. correction of poor graft function following allogeneic hematopoietic stem cell transplantation [13-16]. In the autologous setting, CD34 selected transplants retain some relevance for tumor cell purging, such as in neuroblastoma $[17,18]$. The rationale for CD3/CD19 depletion of haplo-identical allogeneic grafts was the expectation that co-transplanted mature cells, especially Natural Killer (NK)-cells, might provide relevant benefit [19-21]. We will not dismiss the possibility that after the much less efficient T-cell depletion provided by CD3/CD19 depletion (more than one log compared to CD34 selection) therapeutically relevant T-cell doses might remain in the product. Despite strong evidence of (GvHD-) safety and quite satisfactory clinical outcomes with CD3/CD19 depleted transplants, typically supplemented with CD34-selected grafts to achieve the desired hematopoietic stem and progenitor cell (HSPC) megadoses without exceeding the targeted T-cell dose of $50,000 / \mathrm{kg}$ body weight [21,22], CD3/CD19-depleted HSPCs have not become a mass product. Several reasons have likely contributed, including the high cost of the transplant and the advent of alternative haplo-identical transplants, such as TCR $\alpha \beta / \mathrm{CD} 19$ depleted HSPCs $[23,24]$ or unmanipulated bone marrow in combination with post-transplant intermediate-dose cyclophosphamide, which is safe and provides reasonable immune reconstitution [25-30]. We propose that inconsistent cell processing results during CD3/CD19 depletion, as demonstrated by the analyses reported here, may have contributed to its limited adoption. These inconsistencies arise despite use of quality-controlled devices, reagents 
and consumables, with multiply validated, Good Manufacturing Practice (GMP) compliant, rigid manufacturing protocols disseminated by the manufacturer of the materials, in the hands of a professional GMP-team consistently successfully manufacturing a host of other, much more complex products.

\section{MATERIALS AND METHODS}

Mobilized apheresis products from haplo-identical family donors were collected by the apheresis services supporting the respective transplant centers, subjected to quality control in agreement with locally specified quality attributes and released by a Qualified Person. The products were hand-carried by designated couriers at $4-8^{\circ} \mathrm{C}$ in temperature-controlled containers. Products were processed within $24 \mathrm{~h}$ of the end of the apheresis. Product quality varied widely, reflecting typical donor variability but, more importantly, the 10-fold difference in recipient weight (median, $45 \mathrm{~kg}$, interquartile range $27-54 \mathrm{~kg}$, range $8.4-83 \mathrm{~kg}$ ) and accordingly, difference in target doses for CD34+ and T-cells. In most cases, apheresis products were asymmetrically divided, for one part to be subjected to $\mathrm{CD} 3 / \mathrm{CD} 19$ depletion, and the remainder to CD34 selection. Collection of sufficient cells provided, the fraction slated for CD3/CD19 depletion reflected the maximum cell dose for total cells, T- or B-cells allowed by the manufacturer (Miltenyi Biotech (MACS), Bergisch Gladbach, Germany) for reagent kits and tubing set, whichever cell population turned out to be limiting. The remainder was subjected to CD34 selection and is not considered here. CD3/CD19 depletion followed company-provided protocols as previously described, without any modifications, using commercially available reagents throughout. In brief, platelets were removed from the apheresis product by soft-spin, the white blood cells (WBCs) were re-suspended in MACS buffer, albumin-supplemented saline. Antibody-beadcomplex was added as manufacture-recommended. A depletion tubing set 161-01 (Miltenyi Biotech) was used with the cognate Depletion program on CliniMACS (Miltenyi Biotech). Depicted in Table 1 are the attributes of the fraction subjected to CD3/CD19 depletion. The process was initiated on the morning after the apheresis, approximately $18 \mathrm{~h}$ after its end; in one case, the products from two successive aphereses were combined and subjected to $\mathrm{CD} 3 / \mathrm{CD} 19$ depletion, at which time the first apheresis product was 24-h old. Quality controls were performed on incoming apheresis products and target cell bags. The volume was assessed by gross product weight corrected for tare and assuming $1 \mathrm{~g}=1 \mathrm{~mL}$. Concentrations of WBC and five-way differential were measured with Sysmex XT1800i (Norderstedt, Germany), although eosinophils and basophils were neglected for the purpose of these analyses. CD34+ cells (HSPCs) in the apheresis product and end product, as well as T-cells in the apheresis product were enumerated by singleplatform flow cytometry, using Becton-Dickinson (BD) Canto II (BD, Heidelberg, Germany) with Diva software. CD20+ and CD56+ cells before and after depletion as well as T-cells after depletion were enumerated using an in-house generated multi-parametric flow cytometry panel containing anti-CD45, anti-CD34, anti-CD3, anti-CD20, anti-CD56 and anti-CD14, as well as 7-aminoactinomycin (7AAD) as a viability dye (all antibodies and 7AAD:BD). The latter panel is optimized and formally validated for enumeration of very low frequencies of T- and B-cells, whereby T- and B-cells are quantified by normalizing their frequency against International Society for Hematology and Graft Engineering (ISHAGE, now ISCT)-gated CD34+ cells according to the multi-color panel and the concurrently analyzed CD34+ concentration from the single platform assay (Stem Cell Enumeration (SCE), BD) [31]. Sterility was assessed using the European Pharmacopoeia (EP)-conforming rapid test "BacT/Alert" (BioMérieux, Marcy-l'Étoile, France) as described [32]; all products were negative for microbial growth.

Data were extracted in a pseudonymized fashion from the batch records. Analyses represent our regulatory and JACIE-mandated efforts at periodic product quality review. The Goethe University Medical School ethics committee has confirmed that such exercise does not require specific donor consent. Log-depletion was calculated as $\log _{10}$ (total cell number after depletion/total cell number before depletion). Descriptive statistics were calculated and graphs drawn in Excel 2010 (Microsoft, Redmond, WA).

Table 1 Product properties: median, interquartile range (IQR) and range for product-defining values before and after manipulation are presented for all consecutive CD3/CD19-depletion performed between 2012 and 2020

\begin{tabular}{|c|c|c|}
\hline & Apheresis product & Depleted product \\
\hline & Median (IQR/range) & Median (IQR/range) \\
\hline Volume $[\mathrm{mL}]$ & $258(193-310 / 130-380)$ & $206(155-224 / 99-292)$ \\
\hline $\mathrm{WBC}\left[\times 10^{9}\right]$ & $61(57-74 / 30-105)$ & $35(30-44 / 18-77)$ \\
\hline $\mathrm{CD} 34+$ frequency $[\% \mathrm{CD} 45+]$ & $0.78(0.65-0.92 / 0.13-2.3)$ & $1.0(0.86-0.1 .50 / 0.15-4.13)$ \\
\hline CD34+ total dose $\left[\times 10^{6}\right]$ & $529(246-577 / 131-809)$ & $408(200-534 / 119-594)$ \\
\hline CD $34+$ dose $\left[\times 10^{6} / \mathrm{kg}\right]$ & $20.06(8.71-15.14 / 3.43-66.47)$ & $9.42(6.90-10.34 / 3.15-60.70)$ \\
\hline CD3+ frequency [\% CD45+] & $24(21-28 / 12-36)$ & $0.006(0.005-0.016 / 0.002-0.079)$ \\
\hline $\mathrm{CD} 3+$ total dose $\left[\times 10^{6}\right]$ & $15,473(14,629-16,586 / 10,354-29,934)$ & $2.2(1.8-3.1 / 0.9-13.1)$ \\
\hline $\mathrm{CD} 3+$ dose $\left[\times 10^{6} / \mathrm{kg}\right]$ & $443(316-549 / 232-1755)$ & $0.053(0.049-0.093 / 0.034-0.386)$ \\
\hline Monocytes [\% CD45+] & $22(18-29 / 15-32)$ & $30(27-35 / 22-51)$ \\
\hline Granulocytes [\% CD45+] & $31(27-34 / 16-38)$ & $7.6(4.7-14.3 / 2.2-25.9)$ \\
\hline CD56/16+ frequency [\% CD45+] & $4.6(3.8-6.2 / 2.4-22.8)$ & $4.6(3.8-8.9 / 1.6-25.5)$ \\
\hline CD56/16+total dose $\left[\times 10^{9}\right]$ & $3.2(2.5-4.0 / 1.4-9.5)$ & $2.5(1.1-3.2 / 0.4-6.0)$ \\
\hline CD56/16+ dose $\left[\times 10^{6} / \mathrm{kg}\right]$ & $71(60-199 / 25-574)$ & $39(21-96 / 13-385)$ \\
\hline $\mathrm{CD} 20+$ frequency $[\% \mathrm{CD} 45+]$ & $4.4(3.5-5.3 / 1.7-8.1)$ & $0.1(0.01-0.17 / 0.01-0.27)$ \\
\hline $\mathrm{CD} 20+$ total dose $\left[\times 10^{6}\right]$ & $2604(2305-3358 / 1322-4595)$ & $32.4(8.2-59.6 / 1.6-135.2)$ \\
\hline $\mathrm{CD} 20+$ dose $\left[\times 10^{6} / \mathrm{kg}\right]$ & $68(64-79 / 21-547)$ & $0.889(0.388-1.673 / 0.059-3.210)$ \\
\hline
\end{tabular}




\section{RESULTS AND DISCUSSION}

A total of 13 products from 14 aphereses were processed over the course of 8 years. All preparations initially proceeded without planned or unplanned deviations. In two cases, a far less than the expected -3.5 to $-4.0 \log$ T-cell depletion was achieved. In one of these, the product was subjected to a second round of antibody incubation and column separation. The successive depletion cycles succeeded in reducing T-cell dose to a more typical -3.47 log-depletion, to $18,000 \mathrm{~T}$-cells $/ 10^{6} \mathrm{CD} 34+$ cells. A root cause analysis failed to identify reasons for the process failure; all reagents were, of appropriate quality, cell numbers in the apheresis product were well within the manufacturer-suggested range for the antibody dose and column capacity; a handling error was not apparent. The typical, and after the second depletion cycle markedly above-average, depletion of B-cells from the product support the impression that handling and device function during both runs were flawless. Unidentified product or donor properties seem to be responsible. Inconsistent antibody quality would be an alternative explanation. In their reply to our customer complaint, the manufacturer reported that no other complaints had been received for the batch, rendering deficient $\mathrm{CD} 3$ reagent an unlikely explanation. The re-depletion was recorded as a deviation; the product was released as within specification. For the second inefficiently T-cell depleted product, a second depletion was not attempted, since the bulk of the desired CD34+ cell dose, $3.5 \times 10^{6} / \mathrm{kg}$, could be administered as a CD34-selected graft, topped up with part of the CD3/CD19-depleted graft containing only $1.5 \times 10^{6} / \mathrm{kg} \mathrm{CD} 34+$ cells, for a total dose of T-cells from both products combined of the targeted $50,000 / \mathrm{kg}$ (and of $5 \times 10^{6} / \mathrm{kg}$ of HSPCs). The practice of combining CD34-selected and CD3/ CD19-depleted product to achieve the desired HSPC doses without exceeding the targeted T-cell dose was previously reported, as was the occasional need to perform a second round of column purification [22].

On average, approximately $80 \%$ of the CD34+ cells and $55 \%$ of the NK-cells were recovered, similar for CD34+ cells and slightly inferior for NK-cells than in a previously reported series [22]. The one outlier for CD34+ cells, with a recovery of only $52 \%$, is the product which, because of insufficient T-cell depletion, had been subjected to two depletion cycles. Excessive cell loss would indeed be expected, given the many centrifugation cycles, two CliniMACS runs, temporally extended processing and repeated quality control sampling which all removed some cells. The next worst recovery for $\mathrm{CD} 34+$ was $69 \%$, a figure well within the range of what is also achieved with CD34 selection, i.e. recovery for $12 / 13$ depletions was perfectly adequate. Average log depletion of T-cells approached -4 , and of B-cells -2 . T-cell depletion was thus in a similar range, possibly marginally more efficient, than in the aforementioned series [22], while B-cell depletion was markedly less effective. The average residual T-cell dose per million CD34+ cells was 5700; the typically targeted dose of 5 million CD34+ cells $/ \mathrm{kg}$ of the recipient thus contained $28,500 \mathrm{~T}$-cells $/ \mathrm{kg}$, well below the targeted dose of 50,000 T-cells $/ \mathrm{kg}$. Irrespective of the T-cell dose, T-cell add-back to reach the targeted dose was not requested by the clinicians. As shown in Figure 1, eight out of 13 products contained fewer than 10,000 T-cells/million CD34+ cells so that patients could have been transplanted with the CD3/CD19depleted grafts alone. However, clinicians typically requested at least part of the concurrently CD34-selected graft, even if the

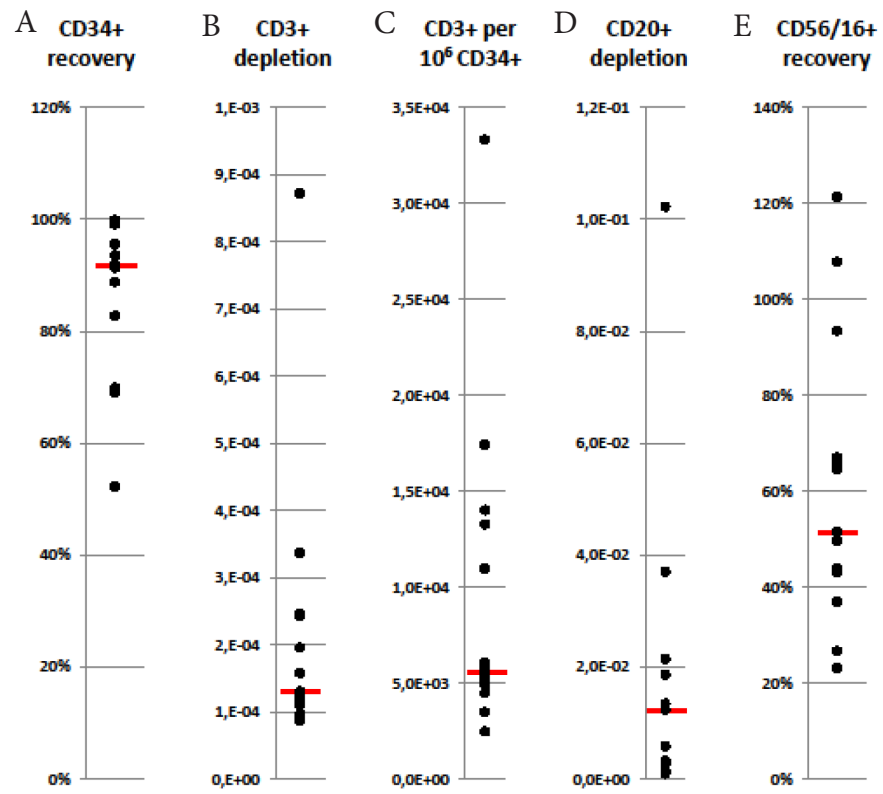

Figure 1 Outcomes of CD3/CD19-depletions: CD34+ cell recovery (A), CD3+ cell depletion (B), number of T-cells per 1 million CD34+ cells (C), CD20+ cell depletion (D) and CD56/16+ cell recovery (E) are depicted. Recovery and depletion are calculated as the total number of post-depletion cells divided by pre-depletion cells, thus accounting for all cell loss during processing and due to quality control sampling. T-cell dose per million CD34+ cells, arguably the most patient-relevant value, is calculated as post-depletion T-cells (total) divided by CD34+ cells (total $\left./ 10^{6}\right)$. Each dot represents one depletion process, the bar marking the median ( $n=13$ depletions).

T-cell content of the CD3/CD19-depleted graft was very low, with the aim of maximizing the HSPC dose.

The first take-home message, therefore, is that $\mathrm{CD} 3 / \mathrm{CD} 19$ depletions are requested quite infrequently, in spite of the fact that our center exclusively serves at least three transplant programs with these products. With respect to the possibility of a learning (or unlearning) effect, for none of the outcome parameters considered, i.e. CD34 cell recovery, $\mathrm{T}$ - and B-cell depletion, was an order effect suggested, and the two inefficient T-cell depletions were observed in years 2 and 8 . The preparations were done by highly experienced GMP personnel; the operators performing the two inefficient depletion runs were, if anything, the more experienced in the team. Operators had maintained proficiency by regularly performing the much more frequent $\mathrm{CD} 34$ selections with the same technology. As mentioned above, a root cause analysis failed to suggest a reason for the inefficient depletions, whether process- or product-inherent.

A second message is that, despite conscientious use of wellvalidated standard operating procedures, the degree of depletion is quite variable, and a relevant number of depletions fail to achieve desired outcomes. We posit that failure to consistently produce largely T- and B-cell-free transplants with the CD3/CD19 depletion technology is likely an underreported phenomenon which is, at least in part, responsible for the relatively poor adoption of this product.

Thirdly, inefficient depletions can be rescued by repeating the process, which was previously also suggested by Huenecke et al. [22], although significant excess HSPC attrition should be regularly 
expected. Because of the paucity of selections, it is not possible to stock "rescue antibody" and kits. These must thus be ordered as immediate delivery which, besides considerable costs, will see the product age for an additional day, with the expected additional cell loss. Thirdly, it is apparent that T-cell- and particularly B-celldepletion by CD3/CD19-depletion is markedly less efficient than by CD34 selection, by approximately one and two common log. Depletion of T-cells in CD34 selected grafts was shown in several studies to lie in the range of -5 to -6 log depletions $[22,33,34]$, whereas T-cell depletion in CD3/CD19 depleted grafts did not exceed $-4 \log$ depletion [22].

Even though the manufacturer does not disclose the antibody clone for either CD34+ selection or CD3/CD19 depletion, given the availability of the technology, implicates that the monoclonal antibodies used for immunomagnetic manipulations are of high and consistent quality. Moreover, the CD3 and CD19 antigens are strongly and selectively expressed on $\mathrm{T}$ - and B-cells, respectively, much stronger than the CD34 antigen is on stem/progenitor cells, rendering weak labeling as a cause of failed depletion a less likely possibility. One difference potentially affecting marking and retention probability is the frequency of the cells being labeled in both procedures. CD34+ cells account for approximately $1 \%$ of all nucleated cells in an apheresis product, whereas T- and B-cells can add up to $40 \%$ and more of the WBCs in a given apheresis product. Overloading of the column with labeled cells was shown to influence the outcome of the procedure [35].

It is impossible to apply established criteria for robust processes $[36,37]$ in pharmaceutical manufacturing to procedures done as seldom as 13 times in 8 years. Nevertheless, failure to achieve the desired T-cell depletion in 15\% (two out of 13) of the manufactured products suggest inconsistency in the process, especially because a root cause analysis did not yield any result, and since essentially similar processes (CD34+ cell selection) provide more consistent results.

Clinical evidence with CD3/CD19-depleted grafts teaches us that with use of anti-thymocyte globulin during conditioning and effective GvHD prophylaxis severe GvHD is typically avoided, and post-transplant lymphoproliferative disease is not an excessively frequent occurrence [19-21]. The quality of the typical CD3/CD19 depleted graft is thus obviously suitable.

In summary, we are reporting inconsistent outcomes for $\mathrm{T}$ - and B-cell depletion by CD3/CD19 depletion with the CliniMACS technology, despite a rigorous manufacturing process, which is undesirable given the irreplaceability of these products.

\section{CONFLICTS OF INTEREST DISCLOSURE}

$\mathrm{HB}$ has received research funding and speakers' fees from Miltenyi Biotech, manufacturers of the technology used here. EW and ES have no declarations.

\section{AUTHORS' CONTRIBUTION}

EW and HB analyzed the data and co-wrote the manuscript. ES bears the overall responsibility for the work. All authors have read and approved the manuscript.

\section{ACKNOWLEDGMENTS}

The consistently excellent, dedicated work of the cell therapy laboratory operators is acknowledged.

\section{REFERENCES}

[1] Aversa F, Martelli MM, Reisner Y. Use of stem cells from mismatched related donors. Curr Opin Hematol 1997;4;419-22.

[2] Aversa F, Tabilio A, Velardi A, Terenzi A, Falzetti F, Carotti A, et al. Hematopoietic stem cell transplantation from alternative donors for high-risk acute leukemia: the haploidentical option. Curr Stem Cell Res Ther 2007;2;105-12.

[3] Klingebiel T, Handgretinger R, Lang P, Bader P, Niethammer D. Haploidentical transplantation for acute lymphoblastic leukemia in childhood. Blood Rev 2004;18;181-92.

[4] Matsuda Y, Hara J, Osugi Y, Fujisaki H, Takai K, Ohta H, et al. Allogeneic peripheral stem cell transplantation using positively selected $\mathrm{CD}^{+} 4^{+}$cells from HLA-mismatched donors. Bone Marrow Transplant 1998;21;355-60.

[5] Martínez C, Urbano-Ispizua A, Rozman C, Marín P, Rovira M, Sierra J, et al. Immune reconstitution following allogeneic peripheral blood progenitor cell transplantation: comparison of recipients of positive $\mathrm{CD} 34^{+}$selected grafts with recipients of unmanipulated grafts. Exp Hematol 1999;27;561-8.

[6] Inoue H, Yasuda Y, Hattori K, Shimizu T, Matsumoto M, Yabe M, et al. The kinetics of immune reconstitution after cord blood transplantation and selected $\mathrm{CD} 34^{+}$stem cell transplantation in children: comparison with bone marrow transplantation. Int J Hematol 2003;77;399-407.

[7] Roy DC, Walker I, Maertens J, Lewalle P, Olavarria E, Selleslag D, et al. ATIR101 administered after T-cell-depleted haploidentical HSCT reduces NRM and improves overall survival in acute leukemia. Leukemia 2020;34;1907-23.

[8] Handgretinger R, Klingebiel T, Lang P, Schumm M, Neu S, Geiselhart A, et al. Megadose transplantation of purified peripheral blood CD $34^{+}$progenitor cells from HLA-mismatched parental donors in children. Bone Marrow Transplant 2001;27;777-83.

[9] Martelli MF, Reisner Y. Haploidentical 'megadose' CD $34^{+}$ cell transplants for patients with acute leukemia. Leukemia $2002 ; 16 ; 404-5$.

[10] Berenson RJ, Bensinger WI, Hill RS, Andrews RG, Garcia-Lopez J, Kalamasz DF, et al. Engraftment after infusion of CD34+ marrow cells in patients with breast cancer or neuroblastoma. Blood 1991;77;1717-22.

[11] Strauss LC, Trischmann TM, Rowley SD, Wiley JM, Civin CI. Selection of normal human hematopoietic stem cells for bone marrow transplantation using immunomagnetic microspheres and CD34 antibody. Am J Pediatr Hematol Oncol 1991;13;217-21.

[12] Martín-Henao GA, Inglés-Esteve J, Cancelas JA, García J. Isolation of $\mathrm{CD} 34+$ hematopoietic progenitor cells in chronic myeloid leukemia by magnetic activated cell sorting (MACS). Bone Marrow Transplant 1996;18;603-9.

[13] Berger M, Faraci M, Saglio F, Giardino S, Ernestina Vassallo E, Prete A, et al. CD34+ selected peripheral blood Stem Cell Boost (SCB) for Poor Graft Function (PGF) or mixed chimerism in pediatric patients, after hematopoietic stem cell transplantation: results of a retrospective multicenter study. Pediatr Transplant 2021;25;e13909. 
[14] Klyuchnikov E, El-Cheikh J, Sputtek A, Lioznov M, Calmels B, Furst S, et al. CD $34^{+}$-selected stem cell boost without further conditioning for poor graft function after allogeneic stem cell transplantation in patients with hematological malignancies. Biol Blood Marrow Transplant 2014;20;382-6.

[15] Larocca A, Piaggio G, Podestà M, Pitto A, Bruno B, Di Grazia C, et al. Boost of CD34+-selected peripheral blood cells without further conditioning in patients with poor graft function following allogeneic stem cell transplantation. Haematologica 2006;91;935-40.

[16] Mainardi C, Ebinger M, Enkel S, Feuchtinger T, Teltschik HM, Eyrich M, et al. CD $34^{+}$selected stem cell boosts can improve poor graft function after paediatric allogeneic stem cell transplantation. Br J Haematol 2018;180;90-9.

[17] Marabelle A, Merlin E, Halle P, Paillard C, Berger M, Tchirkov A, et al. CD34+ immunoselection of autologous grafts for the treatment of high-risk neuroblastoma. Pediatr Blood Cancer 2011;56;134-42.

[18] Handgretinger R, Lang P, Ihm K, Schumm M, Geiselhart A, Koscielniak E, et al. Isolation and transplantation of highly purified autologous peripheral $\mathrm{CD} 34^{+}$progenitor cells: purging efficacy, hematopoietic reconstitution and long-term outcome in children with high-risk neuroblastoma. Bone Marrow Transplant 2002;29;731-6.

[19] Federmann B, Bornhauser M, Meisner C, Kordelas L, Beelen DW, Stuhler G, et al. Haploidentical allogeneic hematopoietic cell transplantation in adults using CD3/CD19 depletion and reduced intensity conditioning: a phase II study. Haematologica 2012;97;1523-31.

[20] Bethge WA, Haegele M, Faul C, Lang P, Schumm M, Bornhauser M, et al. Haploidentical allogeneic hematopoietic cell transplantation in adults with reduced-intensity conditioning and CD3/CD19 depletion: fast engraftment and low toxicity. Exp Hematol 2006;34;1746-52.

[21] Bader P, Soerensen J, Jarisch A, Ponstingl E, Krenn T, Faber J, et al. Rapid immune recovery and low TRM in haploidentical stem cell transplantation in children and adolescence using CD3/CD19depleted stem cells. Best Pract Res Clin Haematol 2011;24;331-7.

[22] Huenecke S, Bremm M, Cappel C, Esser R, Quaiser A, Bonig H, et al. Optimization of individualized graft composition: CD3/ CD19 depletion combined with CD34 selection for haploidentical transplantation. Transfusion 2016;56;2336-45.

[23] Bertaina A, Merli P, Rutella S, Pagliara D, Bernardo ME, Masetti $\mathrm{R}$, et al. HLA-haploidentical stem cell transplantation after removal of alphabeta $+\mathrm{T}$ and $\mathrm{B}$ cells in children with nonmalignant disorders. Blood 2014;124;822-6.

[24] Locatelli F, Merli P, Pagliara D, Li Pira G, Falco M, Pende D, et al. Outcome of children with acute leukemia given HLAhaploidentical HSCT after $\alpha \beta$ T-cell and B-cell depletion. Blood 2017;130;677-85.

[25] Nagler A, Labopin M, Houhou M, Aljurf M, Mousavi A, Hamladji RM, et al. Outcome of haploidentical versus matched sibling donors in hematopoietic stem cell transplantation for adult patients with acute lymphoblastic leukemia: a study from the Acute Leukemia Working Party of the European Society for Blood and Marrow Transplantation. J Hematol Oncol 2021; $14 ; 53$.
[26] Nagler A, Labopin M, Koc Y, Angelucci E, Tischer J, Arat M, et al. Outcome of T-cell-replete haploidentical stem cell transplantation improves with time in adults with acute lymphoblastic leukemia: a study from the Acute Leukemia Working Party of the European Society for Blood and Marrow Transplantation. Cancer 2021;127;2507-14.

[27] Nagler A, Labopin M, Dholaria B, Angelucci E, Afanasyev B, Cornelissen JJ, et al. Comparison of haploidentical bone marrow versus matched unrelated donor peripheral blood stem cell transplantation with posttransplant cyclophosphamide in patients with acute leukemia. Clin Cancer Res 2021;27; 843-51.

[28] Bazarbachi A, Labopin M, Angelucci E, Gülbas Z, Ozdogu $\mathrm{H}$, Arat $\mathrm{M}$, et al. Haploidentical transplantation with posttransplantation cyclophosphamide for $\mathrm{T}$ cell acute lymphoblastic leukemia: a Report from the European Society for Blood and Marrow Transplantation Acute Leukemia Working Party. Biol Blood Marrow Transplant 2020;26;936-42.

[29] Battipaglia G, Labopin M, Kröger N, Vitek A, Afanasyev B, Hilgendorf I, et al. Posttransplant cyclophosphamide vs antithymocyte globulin in HLA-mismatched unrelated donor transplantation. Blood 2019;134;892-9.

[30] Brissot E, Labopin M, Ehninger G, Stelljes M, Brecht A, Ganser A, et al. Haploidentical versus unrelated allogeneic stem cell transplantation for relapsed/refractory acute myeloid leukemia: a report on 1578 patients from the Acute Leukemia Working Party of the EBMT. Haematologica 2019;104;524-32.

[31] Dauber K, Becker D, Odendahl M, Seifried E, Bonig H, Tonn T. Enumeration of viable $\mathrm{CD} 34^{+}$cells by flow cytometry in blood, bone marrow and cord blood: results of a study of the novel BD stem cell enumeration kit. Cytotherapy 2011;13;449-58.

[32] Klarmann D, Sireis W, Hogardt M, Kempf VA, Seifried E, Bonig H. A validation protocol and evaluation algorithms to determine compatibility of cell therapy product matrices in microbiological testing. Cell Tissue Bank 2015;16;311-18.

[33] Perseghin P, Gaipa G, Dassi M, Belotti D, Pogliani EM, Pioltelli P, et al. CD34 stem cell recovery after positive selection of "overloaded" immunomagnetic columns. Stem Cells Dev 2005; $14 ; 740-3$

[34] Panch SR, Reddy OL, Li K, Bikkani T, Rao A, Yarlagadda S, et al. Robust selections of various hematopoietic cell fractions on the CliniMACS plus instrument. Clin Hematol Int 2019;1;161-7.

[35] Braakman E, Schuurhuis GJ, Preijers FW, Voermans C, Theunissen K, van Riet I, et al. Evaluation of 'out-ofspecification' CliniMACS CD34-selection procedures of hematopoietic progenitor cell-apheresis products. Cytotherapy 2008;10;83-9.

[36] EudraLex. The Rules Governing Medicinal Products in the European Union. Volume 4. Good Manufacturing Practice. Guidelines on Good Manufacturing Practice specific to Advanced Therapy Medicinal Products. 2017, pp. 1-90. Available from: https://ec.europa.eu/health/sites/default/files/files/eudralex/vol4/2017_11_22_guidelines_gmp_for_atmps.pdf (accessed July 15, 2021).

[37] Glodek M, Liebowitz S, McCarthy R, McNally G, Oksanen C, Schultz T, et al. Process robustness-a PQRI white paper. Pharm Eng 2006;26;1-11. 